\title{
New ASPN High Efficiency Treatment of ASTM M2 Steel
}

\author{
Edison Silva Lima ${ }^{a *}$ (D), Leonardo Fonseca Oliveira ${ }^{b}$ (D), Alexandre da Silva Rocha ${ }^{c}$ \\ ${ }^{a}$ Instituto Federal de Educação Ciência e Tecnologia do Rio Grande do Sul, Canoas, RS, Brasil \\ ${ }^{b}$ Universidade Federal do Rio Grande do Sul, Laboratório de Conformação Mecânica, Porto Alegre, \\ $R S$, Brasil \\ 'Universidade Federal do Rio Grande do Sul, Laboratório de Conformação Mecânica, Porto Alegre, \\ RS, Brasil
}

Received: September 4, 2020; Revised: November 12, 2020; Accepted: November 29, 2020

\begin{abstract}
Plasma nitriding treatments are applied to achieve excellent surface properties on steel parts and tools. Active screen plasma nitriding (ASPN) does not have the defects presents in direct nitriding plasma treatments (DCPN). However, ASPN require much longer processing times to develop surface layers as deep as those of DCPN. This work presents the development of a biased ASPN treatment system, to investigate the possibility of achieving greater efficiency. The treatments were performed on ASTM M2 steel samples using the same processing parameters in 4 different configurations: DCPN, ASPN and 2 active screen plasma nitriding with biased specimens voltage: one was called "bright bias", because biased voltage is high enough to develop a plasma glow on the samples, and the other "dark bias", where no plasma glow sheath is seen on the samples. The active screen dark biased treatment presented the best results. These results could be understood by the electromagnetic field generated by the bias source promoting the deposition of nitrogen ions on the surface of the part being treated. Therefore, it was demonstrated that the use of dark bias voltage in the active screen treatment in larger reactors is fundamental to achieve good nitriding results in smaller times.
\end{abstract}

Keywords: Plasma nitriding, active screen, ASTM M2, surface treatment, bias voltage.

\section{Introduction}

Plasma nitriding treatments are applied to achieve outstanding surface properties in steel parts and tools, such as higher surface hardness, wear resistance, and corrosion resistance. The standard Direct Current Plasma Nitriding (DCPN) treatment method can develop defects that limit the treatment application. The Active Screen Plasma Nitriding (ASPN) reduces or eliminates defects on the treated materials, such as edge effect and electric arcing surface damage while improving temperature homogeneity in workpieces and eliminating the hollow cathode effect ${ }^{1}$. In the ASPN process, the plasma discharge does not develop directly on the treated parts and the process duration has tends to be longer to obtain layers similar to those achieved in a DCPN process, while using the same nitriding parameters (such as temperature, gas composition and pressure) ${ }^{1}$. As any process under development, several questions arised about the effectiveness of the ASPN process mainly related to the depth and profile of the nitriding layer. Many factors influence the result of treatment. These factors include the distance from the screen to the parts under treatment, and the polarization voltage at which the parts may or may not be subjected during treatment ${ }^{2-4}$. It was observed that in small reactors, where the distance between the active screen and the workpiece is shorter, although plasma is not formed in the workpiece, the thickness of the screen plasma sheath reaches the workpiece, causing nitriding effects similar to

*e-mail: edison.lima@canoas.ifrs.edu.br direct plasma, leading to plasma immersion nitriding ${ }^{5-8}$. However, in larger reactors, parts are farther away from the active screen, and the effect of plasma immersion does not occur, resulting in much smaller nitrided layers for equal processing parameters. In these cases, the use of an auxiliary power source, applying negative potential to the parts being treated (bias voltage) improves the process performance 9 . For further investigation on the ASPN process, we developed an active screen plasma nitriding reactor with polarization voltage where no plasma immersion effect occurs. This work presents the characteristics of the developed equipment and the results of the tests performed with ASTM M2 steel. ASTM M2 was used in this work as there are several papers concerning the nitriding of this material. ASTM M2 is a high speed steel used in the manufacturing of cutting and forming tools, and has a good response to plasma nitriding, reaching high wear resistance values, very important for use in cutters, drills, punchers and dies. The aim was to evaluate the gain in treatment performance by using different strategies of bias voltage application in the treatment and comparing with conventional treatments.

\section{Experimental}

Specimens were manufactured from the ASTM M2 steel $(0,89 \% \mathrm{C}, 4.2 \% \mathrm{Cr}, 4.9 \% \mathrm{Mo}, 6.2 \% \mathrm{~W}, 1.8 \% \mathrm{C}$, in $\mathrm{Wt} \%$ ) having $32 \mathrm{~mm}$ of diameter and $5 \mathrm{~mm}$ of height. The specimens were machined from hardened and tempered bars 
(austenitizing temperature of $1,150^{\circ} \mathrm{C}$ and triple tempering at $540^{\circ} \mathrm{C}$ for 3 hours each). The samples present before the treatments an average hardness of $64 \mathrm{HRC}$. The samples were prepared using 100, 220, 400, 600 and 1200 grade $\mathrm{SiC}$ gridding papers, then polished with $3 \mu \mathrm{m}$ diamond paste. Prior to each treatment, the chamber and samples were cleaned with acetone. In each of the tests, 2 samples properly prepared for nitriding were used, the temperature was monitored in an extra sample, with an attached K-type thermocouple.

Four different plasma nitriding configurations were investigated:

1. DCPN, where samples are placed in the nitriding equipment connected to the power supply and the plasma glow develops directly on the samples surface, without active screen;

2. ASPN, where a cylindrical steel screen is placed in the nitriding chamber connected to the power supply, samples are kept at a floating potential, electrically insulated and inside the screen. In this configuration the plasma glow develops only on the screen;

3. Active screen "bright" bias plasma nitriding (ASBBPN), following the same setup as the ASPN treatment, but the samples are not kept at a floating potential. Instead of it, an auxiliary power supply is connected to samples, this biased voltage is high enough to develop a plasma glow on the samples; and,

4. Active screen "dark" bias plasma nitriding (ASDBPN) had a setup similar to the ASBBPN,

DCPN

Configuration

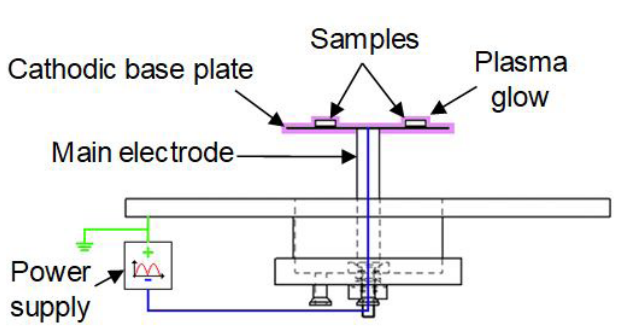

ASDBPN

Configuration

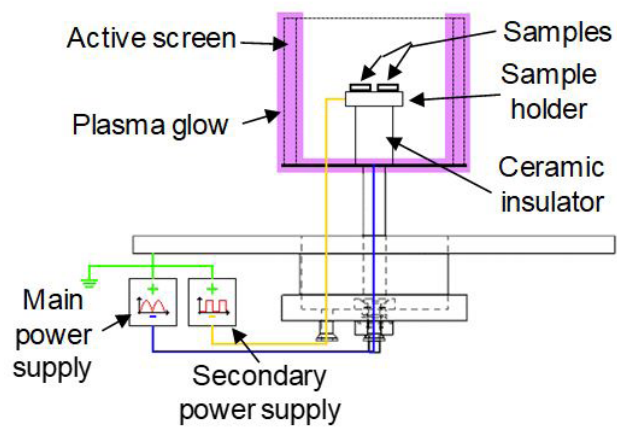

but with a lower biased voltage, where no plasma glow sheath is seen on the samples.

For the treatments, a cylindrical plasma reactor with internal dimensions of $630 \mathrm{~mm}$ in diameter and $680 \mathrm{~mm}$ in height was used. The main power supply, used in the DCPN treatment and connected to the active screen, was a $10 \mathrm{~kW}$ power supply with rectified voltage and frequency of $120 \mathrm{~Hz}$. For the biased treatments, a secondary $8 \mathrm{~kW}$ power supply with $11 \mathrm{kHz}$ pulsed voltage was used to apply the bias voltage to the nitriding samples. All treatments used the same treatment parameters: gas composition of $76 \mathrm{vol} . \% \mathrm{~N}_{2}$ and 24 vol. $\% \mathrm{H}_{2} ; 300 \mathrm{~Pa}$ working pressure, $500^{\circ} \mathrm{C}$ process temperature and $4 \mathrm{~h}$ treatment time. The active screen was constructed in a cylindrical shape with a double layer of expanded AISI 306 stainless steel sheet with 15 x $5 \mathrm{~mm}$ mesh and 0,8 $\mathrm{mm}$ thickness, with dimensions of $215 \mathrm{~mm}$ internal diameter, $245 \mathrm{~mm}$ external diameter and $200 \mathrm{~mm}$ height, with no top cover. For the active screen treatments, samples were arranged on a $105 \mathrm{~mm}$ diameter by $14.6 \mathrm{~mm}$ height AISI 1010 steel sample holder base, electrically insulated from the main electrode and screen by a $52.6 \mathrm{~mm}$ external diameter, $88.4 \mathrm{~mm}$ height ceramic tube, as shown in the diagram presented on Figure 1.

The active screen was connected to the main power supply through the reactor central electrode that supports a $240 \mathrm{~mm}$ diameter and $3 \mathrm{~mm}$ thick 1010 steel cathodic base plate where the active screen sits. The bias voltage of the workpiece is applied through a conductor electrically insulated from the reactor body and active screen.

The electromagnetic fields generated inside the reactor are proportional to the voltages of each process element. The

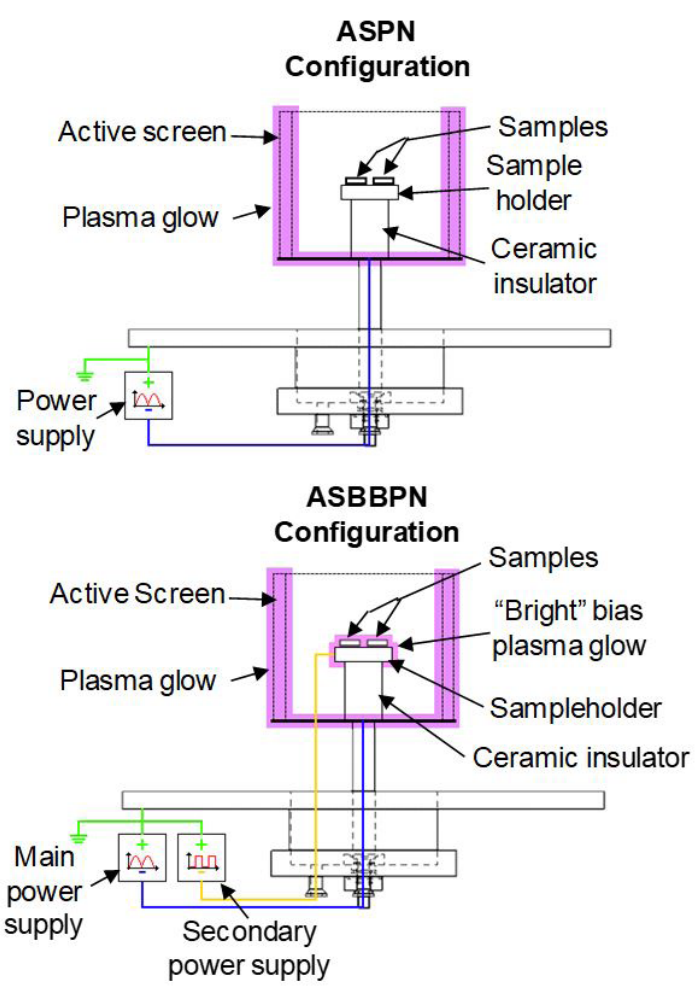

Figure 1. Diagrams for the different treatment configurations. 
reactor walls are connected to the positive potential of the power supply and properly grounded. The main (rectified) power supply is connected to the main electrode, cathodic base plate and active screen. The main power supply is turned on at the start of the process and the ion bombardment of the screen was the only heating source to achieve the treatment temperature of $500{ }^{\circ} \mathrm{C}$; for the bias treatments, the bias voltage was applied only during the nitriding cycle. The maximum voltage needed for the treatments was $490 \mathrm{~V}_{\text {RMS }}$ for the main power supply and $360 \mathrm{~V}_{\mathrm{RMS}}$ for the secondary bias power supply in the ASDBPN and $500 \mathrm{~V}_{\mathrm{RMS}}$ in the ASBBPN. During the treatments the average currents were for the main power supply: 8.5 A on ASDBPN and 6.5 A on ASBBPN. The average polarization currents for the secondary power supply were 0.9 A for ASDBPN and 1.4 A for ASBBPN. The Figure 2 presents the voltage waveform for ASDBPN and ASBBPN.

The Figure 3 shows a schematic representation of the electromagnetic field vectors in the three main situations of interest for this work for ASBBPN and ASDBPN processes. As cyclic voltage has been applied with a frequency of $120 \mathrm{~Hz}$. In (A) the voltage on the active screen is maximum and the voltage in the sample is zero. In (B) the voltages in the active screen and in the sample are of the same intensity. In (C) the electrical voltage in the sample is maximum and the voltage in the active screen is zero. This cycle is continuous and occurs 120 times per second.
After the treatment the nitrided samples were cut with diamond disk and embedded in bakelite. The cross-sections were ground and polished with a diamond paste of $1 \mu \mathrm{m}$ grain size. The polished samples were analyzed trough optical microscopy and microhardness profile. A solution of Nital $2 \%$ was used to etch the samples revealing the microstructure of the nitrided layers observed at the optical microscope. The microhardness profiles were obtained to evaluate the plasma nitrided layers by using a Vickers indenter and $100 \mathrm{~g}$ load applied for $10 \mathrm{~s}$ at each measurement. Non-embedded parts were analyzed for surface hardness, nitrogen concentration depth profiles using Glow-Discharge Optical Emission Spectroscopy (GDOES), and phase analysis using X-ray diffraction technique (XRD) performed on the surface of the samples in the Bragg-Brentano geometry with $\mathrm{Cu}-\mathrm{K} \alpha$ radiation.

\section{Results and Discussion}

\subsection{Optical microscopy}

Figure 4 shows the cross-section micrograph of the etched nitrided samples. For the DCPN and ASDBPN samples, a compound layer (white layer, located in the most superficial area of the samples) is observed. Below the compound layer is the diffusion zone (darker etched zone). The DCPN developed the deepest nitrided case with about $4 \mu \mathrm{m}$ thick compound layer and $86 \mu \mathrm{m}$ deep diffusion zone,

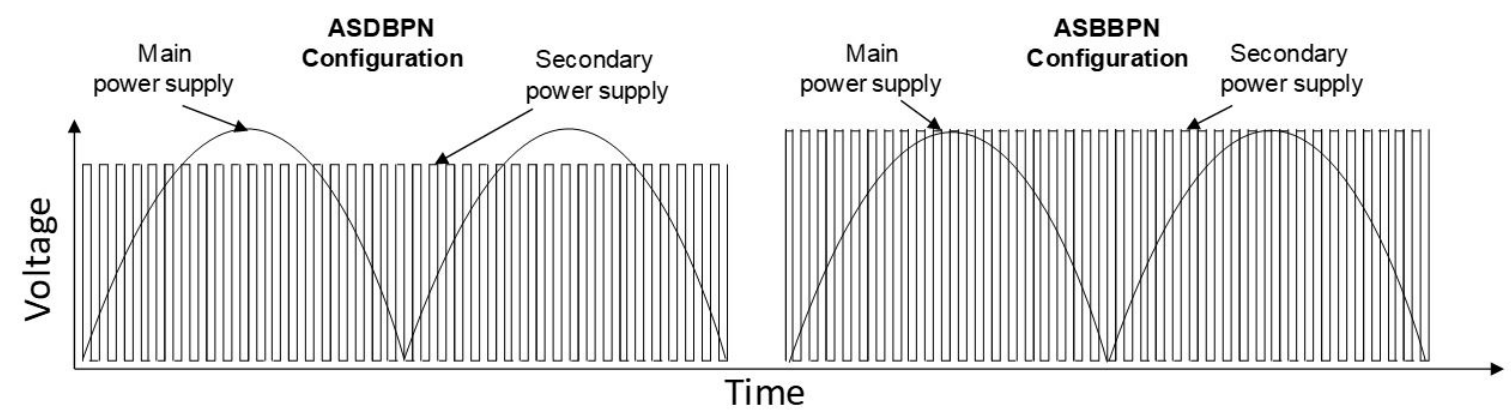

Figure 2. Voltage waveform in active screen (main power supply) and in samples (secondary power supply).
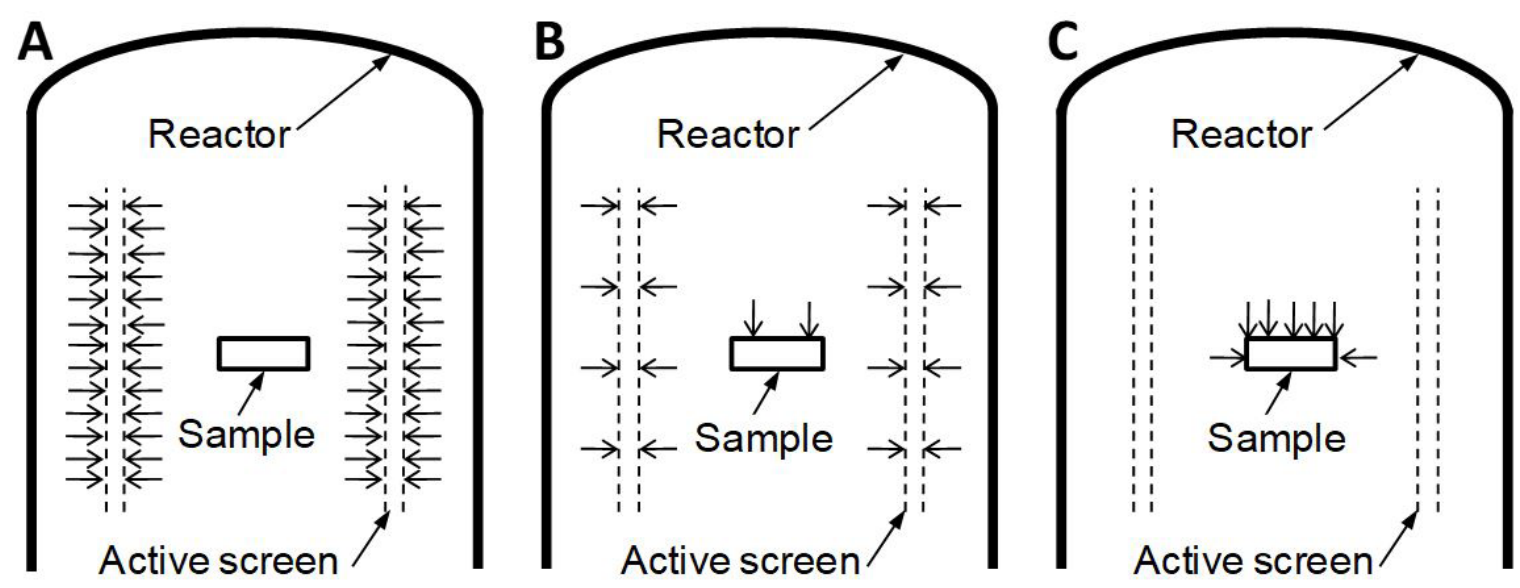

Figure 3. Electromagnetic fields of biased processes. (A) the maximum voltage on the active screen. (B) voltages of the same intensity. (C) the maximum voltage in the sample. 

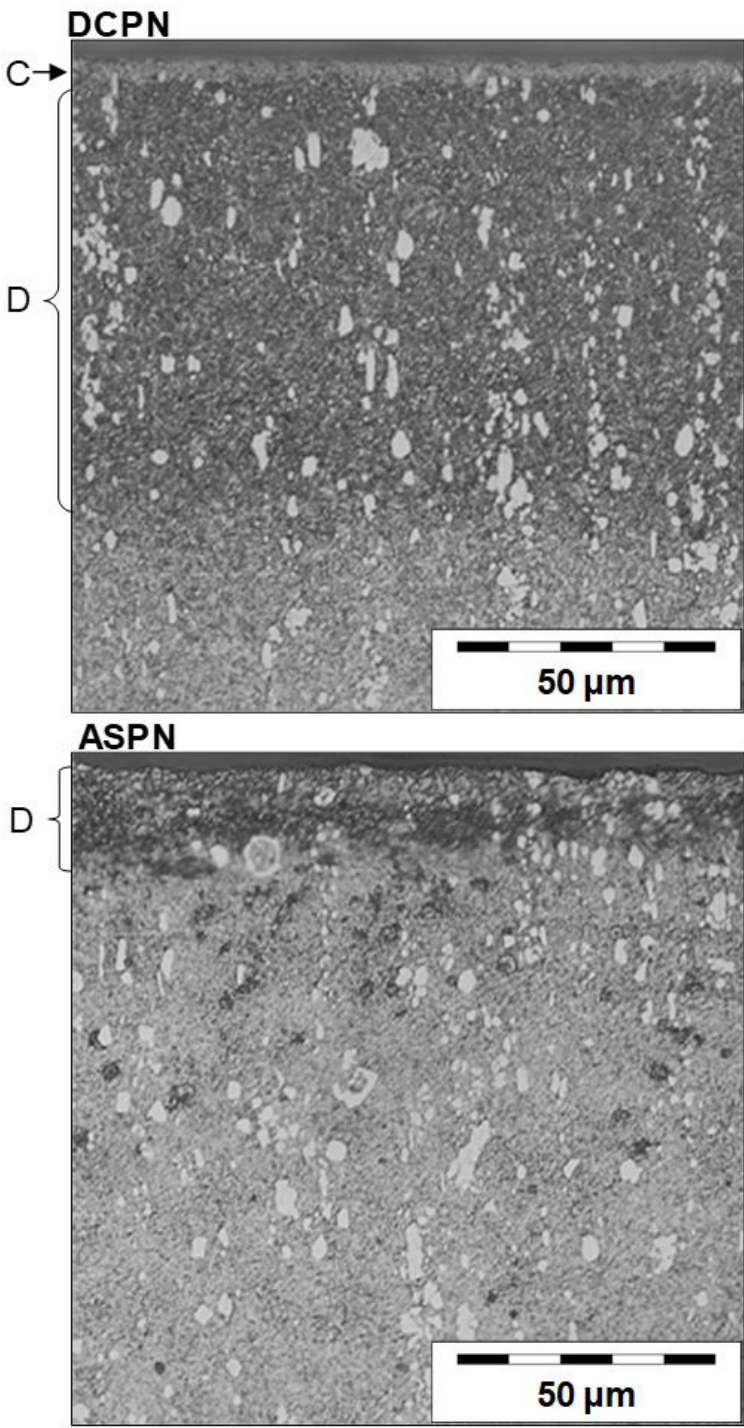

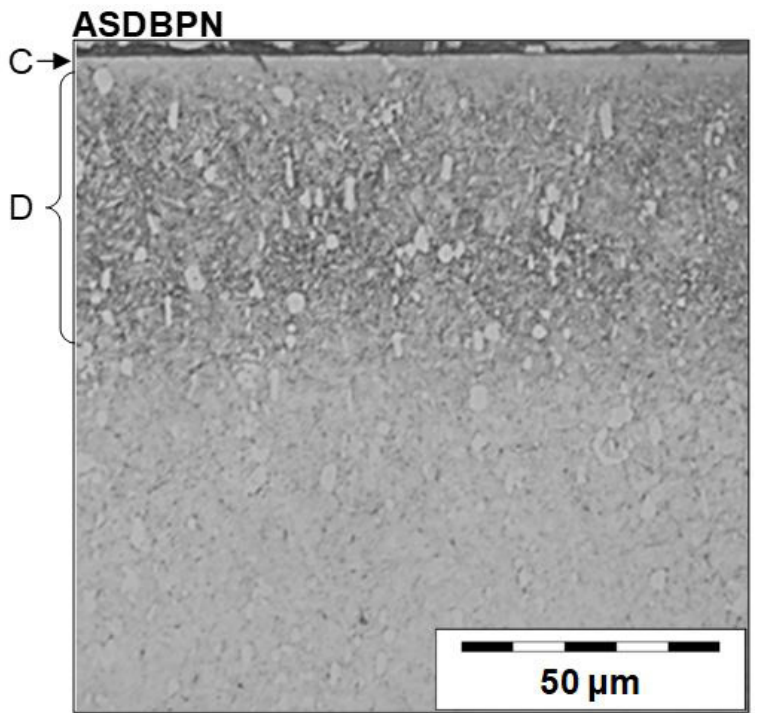

\section{ASBBPN}

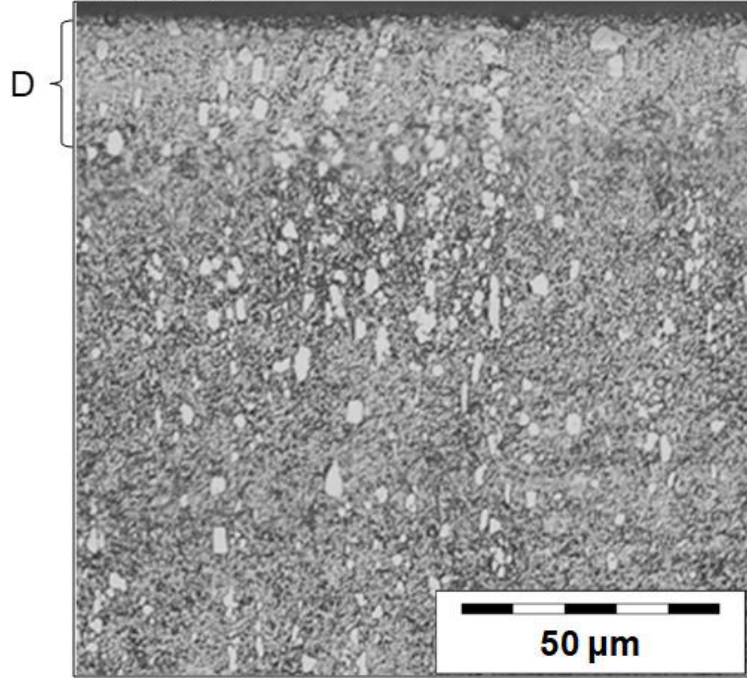

Figure 4. Cross-section optical microscopies of the nital etched nitrided specimens. Nitrided layers are labelled: C - Compound layer and D - Diffusion zone.

the DBPN treatment developed a shallower nitrided depth with a thickness of $3 \mu \mathrm{m}$ and $57 \mu \mathrm{m}$ for the compound layer and diffusion zone respectively. Both ASPN and ASBBPN treatments developed much shallower nitrided depths than the other treatments, with nitrided layers consisting only with diffusion zone of respectively $12 \mu \mathrm{m}$ and $19 \mu \mathrm{m}$.

\subsection{GDOES}

Figure 5 presents the nitrogen concentration profile obtained by the GDOES analysis of the samples. These plots demonstrates the effectiveness of the ASDBPN treatment in terms of nitrogen diffusion in the sample. The concentration profile is very similar to the results obtained by DCPN. Without bias ASPN was ineffective in terms of nitrogen diffusion, mainly due to the distance between samples and active screen. ASBBPN demonstrated the little influence of active screen on the process, since similar results are achieved with DCPN as well as very low plasma densities.

\subsection{Microhardness measurements}

Figure 6 shows the microhardness profile graphs of the nitrided specimens, the measurements presented at " 0 " distance from surface depth was taken from surface microhardness measurements. The nitriding treatments for both DCPN and ASDBPN specimens developed the highest and deepest hardened cases, maintaining hardness above $1200 \mathrm{HV}_{0.1}$ up to $50 \mu \mathrm{m}$ deep. The DCPN sample presented hardness close to $1000 \mathrm{HV}_{0.1}$ at depths greater than 110 micrometers and the ASDBPN sample has hardness above $800 \mathrm{HV}_{0.1}$ up to 110 micrometers. These results are compatible with optical microscopy and the nitrogen concentration profile, proving the effectiveness of the ASDBPN method for these conditions. It is observed that the ASPN and ASBBPN samples did not developed a relevant hardness increase, due to the low nitriding potential achieved with these methods for this steel under the conditions tested. 


\subsection{X-ray Diffraction}

Figure 7 shows XRD patterns for the nitrided and not nitrided specimens. Matrix peaks corresponds to the $\alpha-\mathrm{Fe}$ (C, M)-martensite, where $\mathrm{M}$ refers to the different metallic alloying elements present in the steel composition. The identified carbide phases are either the VC or M6C phases as indicated in the literature ${ }^{10}$.

The diffraction patterns for both DCPN and ASDBPN samples are very similar, indicating that these different nitriding techniques can develop similar nitrided cases with very close properties as seen in the aforementioned results.

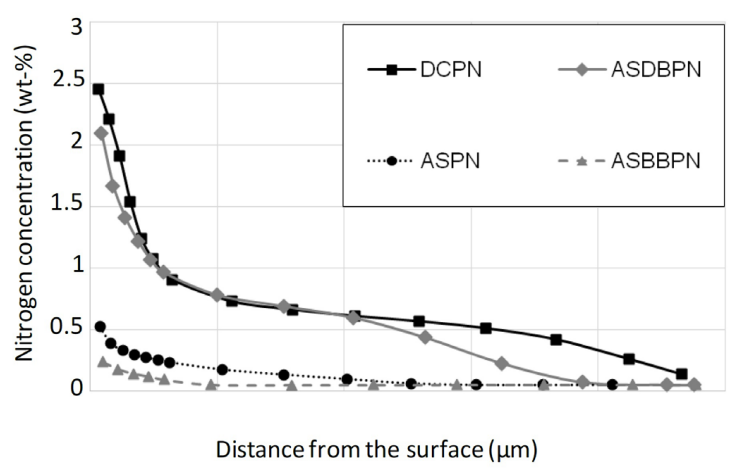

Figure 5. Nitrogen concentration profile for the nitrided specimens.

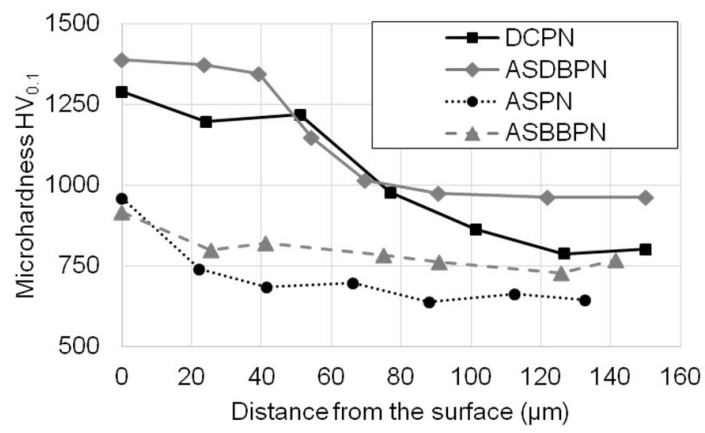

Figure 6. Microhardness profiles for the nitrided specimens.

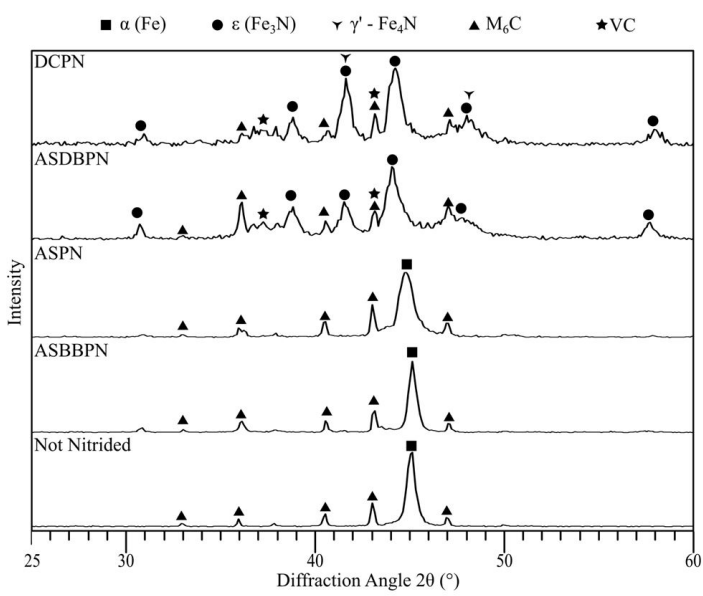

Figure 7. XRD patterns of DCPN, ASDBPN, ASPN, ASBBPN plasma nitrided sample surface and M2 not nitrided sample surface.
The ASPN and ASBBPN samples were comparable to the non-nitrided sample. It is observed that there was very little variation in the diffraction peaks presented for these nitrided samples in relation to the non-nitrided sample. The ASPN and ASBBPN did not develop effective nitriding results for this treatment times.

\subsection{Final Discussion}

The reactor used in this work has enough room to allow the use of an active screen of dimensions in which the influence of plasma immersion of the samples is minimized or even not present. Both DCPN and ASDBPN treatments developed similar results with effective nitriding while the ASPN and ASBBPN treatment configurations promoted little modifications compared to the non nitrided material. The ASPN had the lowest nitriding potential, verified by both, layer depth and hardness increase. There was little nitrogen deposition on the sample surface during treatment, because the sample was far enough from the active screen, the major part of the active species developed in the plasma sheath could not interact to the nitriding parts. We therefore consider that the plasma immersion of these samples did not occurred. Similar results were found in the work of other researchers ${ }^{11,12}$.

For these conditions, the use of bias voltage in the active screen treatment in larger reactors is fundamental for good nitriding results. The ASDBPN presented the best results in terms of nitrided layer with active screen, and the diffusion zone is similar to DCPN. The micro hardness test results indicate that the surface hardness increases as it approaches the surface, very consistent with the GDOES profile. The authors believe that the electromagnetic field generated by the active screen weakens as the sinusoidal voltage of the source connected to it decays, and the electromagnetic field generated by the pulsed voltage in the part at a given time is more intense than that of the active screen, therefore attracting to the sample the ions that promote nitriding. These ions are generated by the active screen plasma and are dispersed within the reactor. Thus, the nitrogen availability on the surface of the part is sufficient for a good response in the adsorption and diffusion of it into the sample. The Figure 8 shows the scheme of such a proposed model.

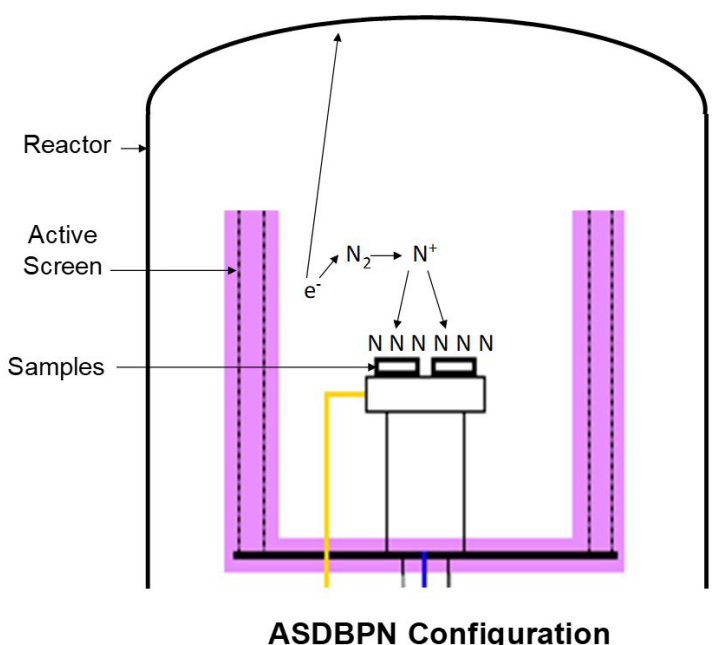

Figure 8. ASDBPN nitriding scheme. 


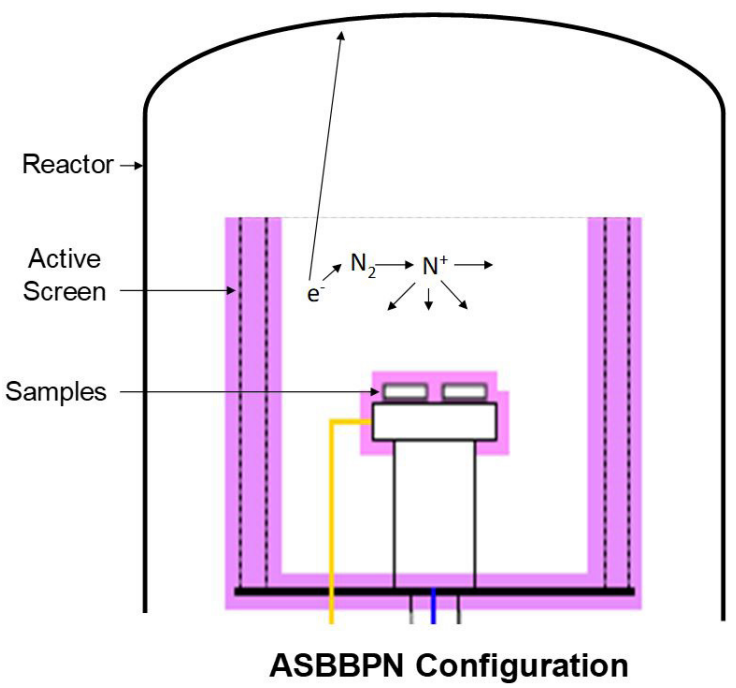

Figure 9. ASBBPN nitriding scheme.

The ASBBPN presented a nitrided layer comparable with pulsed direct nitriding with low plasma density, both in surface hardness and in GDOES profile. The best explanation for the little influence of the active screen in this process is due to the electromagnetic fields generated by the plasma. The nitriding species generated in the active screen plasma cannot reach the samples due to the plasma electromagnetic field generated in the workpiece, leaving the latter as the sole supplier of active nitriding species. The Figure 9 shows the scheme of this model. In this case, the influence of the active screen was minimal, demonstrating the inefficiency of the process when the bias voltages are high enough to generate plasma in the workpiece.

\section{Conclusions}

The electromagnetic field has a great influence on active screen plasma nitriding. In this paper 4 different plasma nitriding configurations have been investigated, conventional direct plasma, active screen without bias, and active screen with bias generating plasma on the workpiece and screen simultaneously (ASBBPN), and with bias on the workpieces but with no glow sheath on samples (ASDBPN). In the process ASDBPN, using the active screen without cover and the bias voltage without plasma in workpiece generated favorable conditions for the nitriding, achieving results similar to direct catodic plasma nitriding (DCPN) but without the undesirable defects. The ASBBPN process and the ASPN without bias didn't achieve enough potential for an effective nitriding of the ASTM M2 steel under investigation.

\section{Ackowledgements}

The authors wish to acknowledge the financial support by the Instituto Federal de Educação Ciência e Tecnologia do Rio Grande do Sul (IFRS), Universidade Federal do Rio
Grande do Sul (UFRGS), Porto University, Coordenação de Aperfeiçoamento de Pessoal de Nível Superior (CAPES, Brasil - Finance Code 001), Conselho Nacional de Desenvolvimento Científico e Tecnológico (CNPq, Brasil, Universal, process number 435795/2018-0), Fundação de Amparo à Pesquisa do Estado do Rio Grande do Sul (FAPERGS, Brasil, process 17/2551-0001023-0) and European Community Erasmus Mundus EBW+.

\section{References}

1. Hubbard P, Partridge JG, Doyle ED, McCulloch DG, Taylor $\mathrm{MB}$, Dowey SJ. Investigation of nitrogen mass transfer within an industrial plasma nitriding system I: the role of surface deposits. Surf Coat Tech. 2010;204(8):1145-50. http://dx.doi. org/10.1016/j.surfcoat.2009.08.029.

2. de Sousa RRM, de Araújo FO, da Costa JAP, Dumelow T, de Oliveira RS, Alves C. Nitriding in cathodic cage of stainless steel AISI 316: influence of sample position. Vacuum. 2009;83(11):1402-5.

3. Hubbard P, Dowey SJ, Partridge JG, Doyle ED, McCulloch DG. Investigation of nitrogen mass transfer within an industrial plasma nitriding system II: application of a biased screen. Surf Coat Tech. 2010;204(8):1151-7. http://dx.doi.org/10.1016/j. surfcoat.2009.08.030.

4. Nishimoto A, Nagatsuka K, Narita R, Nii H, Akamatsu $\mathrm{K}$. Effect of the distance between screen and sample on active screen plasma nitriding properties. Surf Coat Tech. 2010;205(Suppl. 1):S365-8. http://dx.doi.org/10.1016/j. surfcoat.2010.08.034.

5. Corujeira Gallo S, Dong H. Study of active screen plasma processing conditions for carburising and nitriding austenitic stainless steel. Surf Coat Tech. 2009;203(24):3669-75. http:// dx.doi.org/10.1016/j.surfcoat.2009.05.045.

6. Zhao C, Wang LY, Han L. Active screen plasma nitriding of AISI 316L austenitic stainless steel at different potentials. Surf Eng. 2008;24(3):188-92. http://dx.doi.org/10.1179/174329408X271543.

7. Alves C, de Araújo FO, Ribeiro KJB, da Costa JAP, Sousa RRM, de Sousa RS. Use of cathodic cage in plasma nitriding. Surf Coat Tech. 2006;201(6):2450-4.

8. Zhao C, Li CX, Dong H, Bell T. Study on the active screen plasma nitriding and its nitriding mechanism. Surf Coat Tech. 2006;201(6):2320-5.

9. Hubbard P, Dowey SJ, Doyle ED, McCulloch DG. Influence of bias and in situ cleaning on through cage (TC) or active screen plasma nitrided (ASPN) steels. Surf Eng. 2006;22(4):243-7. http://dx.doi.org/10.1179/174329406X122937.

10. Mohammadzadeh R, Akbari A, Drouet M. Microstructure and wear properties of AISI M2 tool steel on RF plasma nitriding at different N2-H2 gas compositions. Surf Coat Tech. 2014;258:56673. http://dx.doi.org/10.1016/j.surfcoat.2014.08.036.

11. Corujeira Gallo S, Dong H. New insights into the mechanism of low-temperature active-screen plasma nitriding of austenitic stainless steel. Scr Mater. 2012;67(1):89-91. http://dx.doi. org/10.1016/j.scriptamat.2012.03.028.

12. Corujeira Gallo S, Dong H. On the fundamental mechanisms of active screen plasma nitriding. Vacuum. 2009;84(2):321-5. http://dx.doi.org/10.1016/j.vacuum.2009.07.002. 